\title{
ALGUNS APONTAMENTOS METODOLÓGICOS PARA A REFLEXÃO SOBRE A URBANIZAÇÃO COMO NEGÓCIO NO CONTEXTO DA MODERNIZAÇÃO
}

\author{
Rafael Faleiros de Padua \\ Doutorando do Programa de Geografia Humana da Universidade de São Paulo \\ rfpadua@usp.br
}

\section{Resumo}

Através de uma discussão conceitual e metodológica embasada em categorias marxistas como acumulação primitiva, trabalho abstrato, atividade, procuramos fundamentar um percurso teórico possível na Geografia, buscando o desvendamento do mundo moderno e da urbanização contemporânea.

Palavras-chave: acumulação primitiva, atividade, trabaIho abstrato, urbanização.

\begin{abstract}
Through a discussion based on conceptual and methodological marxist categories as primitive accumulation, abstract work, activity, we can support a theoretical course in Geography, seeking to unveil the modern world and urbanization contemporany.
\end{abstract}

Key Words: primitive accumulation, activity, abstract work, urbanization.

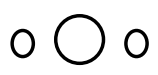

\section{INTRODUÇÃO}

A realidade atual se apresenta com toda a sua complexidade à análise, exigindo da reflexão novos esforços teóricos. A modernização como problema teórico se revela como um elemento importante para a construção de caminhos de entendimento da realidade. Entendemos a modernização como a expansão capitalista, produtora de uma sociabilidade específica e portadora de determinações sociais específicas que se realizam como reprodução geral da sociedade. Diante da "inexorabilidade" com a qual se apresenta, analisaremos a modernização pretendendo realçar os conflitos e o caráter crítico do processo do capital. Do ponto de vista da análise espacial, cumpre pensar uma crítica do processo de produção do espaço, realizando uma crítica à economia política do espaço. A difusão da "inexorabilidade" do processo que apontamos acima provém em grande parte de discursos econômicos que sempre analisam a sociedade através do equilíbrio, enquanto há que se colocar em primeiro plano a crise imanente ao processo de reprodução da sociabilidade capitalista. Tentaremos aqui apontar caminhos possíveis para a discussão da modernização, inserindo nela a problemática urbana.

Pensamos que é preciso deixar clara a necessidade do desvendamento das irracionalidades do processo do capital que se apresentam socialmente como racionalidades. Trata-se da crítica à ideologia do crescimento ilimitado, crítica à idéia de desenvolvimento que vem unida à de modernização, crítica à idéia de progresso. Nesse sentido, a própria concepção de modernização se apresenta como um grande aparato ideológico. É entendendo os conflitos produzidos, chegando às contradições que vislumbraremos uma crítica destas ideologias. Assim, a realidade social, que num primeiro momento (senso comum) aparece como concretude, na análise se revela como a concretização de abstrações. Seguindo Karel Kosik diríamos que a realidade se apresenta como uma pseudoconcreticidade a ser pensada criticamente e com Lefebvre indicaríamos que a crítica passa pela crítica das abstrações concretas. A partir disto, podemos 
pensar a modernização como um processo de abstração, no qual, através do desenvolvimento das forças produtivas, o homem se apropria da natureza cada vez mais envolvido por mediações. É neste sentido que podemos também pensar o espaço inserido no processo de reprodução social como abstração. A reflexão da realidade social nos leva a entendê-lo como mercadoria inserida no processo geral de reprodução da sociedade.

É dessa forma que estamos pensando a necessidade da análise do espaço como abstração, e por isto uma possível crítica à Geografia (Crítica) que, ao valorizar demasiadamente a materialidade dos processos, escamoteou o caráter abstrato do espaço no capitalismo. O aparentemente concreto no primeiro momento da investigação demanda um procedimento de abstração em busca das mediações necessárias para a sua explicação. Nesse percurso, é premente uma reflexão sobre a maneira como o espaço é produzido sob o domínio do capital. As determinações abstratas (com o nível do econômico se sobrepondo ao do político e ao do social) da produção do espaço realizariam o espaço abstratamente, pois envolvido nos mecanismos da valorização. As mediações constituídas no processo histórico de apropriação da natureza pelo homem (desenvolvimento das forças produtivas) se reproduzem contraditoriamente, já que ao mesmo tempo em que ampliam a dominação do homem sobre a natureza, se produzem como determinações abstratas que dominam e fragmentam a vida do homem.

Procuraremos então encontrar argumentos para pensar a abstração do espaço ao longo do processo histórico. É certo que esta abstração está inserida no processo mais amplo do desenvolvimento das forças produtivas, onde o espaço é condição fundamental de realização.

Temos o desafio de, imbuídos de um pensamento que é histórico (construído ao longo do tempo), pensar a realidade, confrontando esta realidade ao pensamento, construindo um novo pensamento, elaborando novas idéias. É um processo cumulativo e de superação do próprio conhecimento. É preciso acrescentar que, na pesquisa científica, estamos sempre no limiar entre o parecer ser e o ser e essa é a questão de fundo deste texto. É preciso distinguir a aparência da essência, tomando-os como momentos (relativos) da construção do conhecimento. Vivemos em uma sociedade e num momento histórico nos quais as mistificações governam as ações, produzindo e mediando as relações sociais. Diante disso, a tarefa do conhecimento científico é desmascarar as mistificações, tirando os véus que separam a vida social de sua realização concreta, de sua emancipação. No caso da Geografia a questão central do parecer ser e do ser é talvez complexificada dado que os processos sociais se realizam necessariamente no espaço, produzindo um espaço. $\mathrm{Na}$ análise, o espaço - a cidade, os lugares, o meio ambiente, a paisagem, etc. — aparece como uma dimensão concreta dos processos sociais, correndo-se o risco de tomá-lo prontamente como essência quando ele (num primeiro momento da explicação) é aparência dos processos sociais. Mesmo nas correntes ditas críticas da Geografia corre-se e comete-se esse erro. Em outras vertentes, como a Geografia Cultural ou Geografia Humanista, aprofunda-se no erro, se perdendo numa metonimização do mundo, tomando a parte pelo todo. Procuraremos discutir a necessidade de caminhos possíveis de busca pela essência, refletindo caminhos teóricos nesse sentido.

Na história da Geografia, apesar de sempre estar subjacente uma análise espacial, o espaço demorou a se configurar como um conceito chave. É com a Geografia teorético-quantitativa, a partir da década de 1950, que o espaço será objeto de reflexão teórica e tomado como conceito chave, mas numa explicação baseada no positivismo lógico, a-histórica, em que a explicação era realizada através de modelos e esquemas matemáticos ${ }^{1}$. Ou seja, uma explicação que reduzia a realidade de tal modo a modelos matemáticos que as determinações sociais dos fenômenos eram escamoteadas e o próprio conteúdo (histórico) do espaço era esvaziado. 
A Geografia Crítica (que se desenvolve a partir da década de 1960), por outro lado incorporando o marxismo na análise geográfica, baseia sua análise no materialismo histórico, pensando teoricamente o espaço como produto da reprodução capitalista. Aqui também o espaço ocupa o centro da análise, mas, diferentemente do conteúdo abstrato da explicação quantitativa, busca-se a investigação do espaço concreto produzido pelas relações sociais ${ }^{2}$.

A Geografia está diante do mundo do presente e deve enfrentar as máscaras que enevoam o entendimento da realidade. Achar o fundamento para pensar o virtual. Por isso, estando imersos no modo de produção capitalista, cumpre-nos chegar ao que fundamenta este modo de produção que abarca a realidade inteira como determinação econômica. Através de Marx, chegamos ao trabalho social como fundamento da produção do valor, e ao conteúdo do trabalho social, a exploração dos homens pelos homens, com a necessária expropriação de uma parcela grande da população que fica jogada à própria sorte, tendo como única propriedade a própria força de trabalho a ser vendida num mercado de trabalho. A sociabilidade capitalista se desenvolve a partir dessa expropriação e com toda violência que ela implica, com a transformação de uma parcela da população em "trabalhadores livres" ao serviço da valorização do valor. A acumulação primitiva estudada por Marx revela um momento fundamental da ruptura que representa 0 desenvolvimento do capitalismo propriamente dito, quando este passa a ser uma determinação da sociabilidade, e como uma tendência a se tornar mediação da reprodução da sociedade como um todo. É por isso que o seu estudo contribui para o esclarecimento da sociedade atual, já que a acumulação primitiva (expropriação dos meios de vida e de produção) como fundamento se repõe no decorrer da história do desenvolvimento do capitalismo e é fundamental para a sua reprodução. Este estudo de Marx é interessante também para entendermos como se dá a naturalização da exploração do trabalho, para tanto, algumas considerações sobre a acumulação primitiva são necessárias. Posteriormente, investigaremos outros momentos fundamentais da realidade atual, a instituição do trabalho alienado e a abstração do espaço e do tempo no mundo moderno através de alguns apontamentos sobre a pesquisa sobre a urbanização atual.

\section{A ACUMULAÇÃO PRIMITIVA COMO CONDIÇÃO DO CAPITALISMO}

Para que o capitalismo se desenvolvesse efetivamente foi necessária a separação radical dos trabalhadores de seus meios de produção. A acumulação primitiva produz relações especificamente capitalistas, já que faz com que os trabalhadores não possuam nada além de sua força de trabalho, sua força pessoal, enquanto que as condições de transformação desta força em força produtiva se encontram do lado dos senhores (capitalistas). Através do contrato de trabalho, se sustenta as duas classes antagônicas, os senhores (capitalistas) e os servos (trabalhadores), como se fosse uma relação de troca razoável. A acumulação primitiva tal qual Marx expôs revela a violência embutida nesta produção do trabalhador assalariado e o quanto de irracionalidade está contida nesta troca aparentemente honesta e plausível socialmente.

Os capitalistas só emergiram como força depois que as relações feudais se dissolveram, ou seja, depois que se dissolveram as amarras que impediam a exploração do homem pelo homem. A gênese do assalariado e do capitalista tem seu ponto de partida na servidão feudal, pois a acumulação primitiva é a metamorfose da servidão feudal em exploração capitalista. Assim, a base da acumulação primitiva é a expropriação dos camponeses, com a expropriação das terras comunais e a transformação das terras de trabalho dos camponeses em pastagens para a produção de lã (fins do século XV e todo o século XVI). Com a reforma protestante, os bens da igreja também foram expropriados, o que acontece conjuntamente com um avanço da expropriação dos camponeses. Segundo Marx, 
O roubo dos bens da Igreja, a alienação fraudulenta dos domínios do estado, a ladroira das terras comuns e a transformação da propriedade feudal e do clã em propriedade privada moderna, levada a cabo com terrorismo implacável, figuram entre os métodos idílicos da acumulação primitiva. Conquistaram o campo para a agricultura capitalista, incorporaram as terras ao capital e proporcionaram à indústria das cidades a oferta necessária de proletários sem direitos"3.

Com este estado de coisas vai se configurando um sistema em que a propriedade privada se sobrepõe à propriedade costumeira. E para a afirmação e naturalização da formação do proletariado, vai sendo elaborada uma legislação sangrenta (nos termos de Marx) para combater o que chamavam de vagabundagem nas cidades, num contexto em que o número de proletários era maior que o de postos de trabalho (fim do século XV e século XVI). Os desempregados eram tratados como vagabundos e delinqüentes voluntários e eram enquadrados nas leis que visavam disciplinar os camponeses expropriados no trabalho assalariado. "Ao progredir a produção capitalista, desenvolve-se uma classe trabalhadora que por educação, tradição e costume aceita as exigências daquele modo de produção como leis naturais evidentes" ${ }^{4}$.

Na acumulação primitiva, o operário passa a se ver dependente do capital, mas o domínio da burguesia é avalizado por um aparato estatal que censura as uniões operárias e outras formas de organização do proletariado.

Além da formação do proletariado para trabalhar nas indústrias, a acumulação primitiva também produziu um mercado interno, com a destruição da indústria doméstica rural. Essa destruição é um momento necessário para a formação do mercado interno para os produtos industrializados. Todo esse processo de produção de uma sociedade com novos pressupostos se realizou através da violência estatal, ela mesma tornada uma potência econômica. Violência esta exercida também nas colônias, com a dominação dos territórios, expropriação das riquezas, comércio de escravos, etc.

Marx diz que a acumulação primitiva "significa apenas a expropriação dos produtores diretos, isto é, a dissolução da propriedade privada baseada no trabalho pessoal, próprio" 5. Assim, o passo fundamental para a formação das relações especificamente capitalistas se dá com a destruição do trabalho do pequeno produtor que trabalhava com seus próprios meios de produção, conformando abstrações que se concretizam socialmente.

Sua destruição (do trabalho do produtor direto), a transformação dos meios de produção individualmente dispersos em meios socialmente concentrados, da propriedade minúscula de muitos na propriedade gigantesca de poucos; a expropriação da grande massa da população, despojada de suas terras, de seus meios de subsistência e de seus instrumentos de trabalho, essa terrível e difícil expropriação, constitui a pré-história do capital. Ela se realiza através de uma série de métodos violentos dos quais examinamos apenas aqueles que marcaram sua época como processos de acumulação primitiva do capital. A expropriação do produtor direto é levada a cabo com o vandalismo mais implacável, sob o impulso das paixões mais infames, mais vis e mais mesquinhamente odiosas. A propriedade privada, obtida com o esforço pessoal, baseada por assim dizer na identificação do trabalhador individual isolado e independente com suas condições de trabalho, é suplantada pela propriedade capitalista, fundamentada na exploração de trabalho alheio, livre apenas formalmente ${ }^{6}$.

Com isso, a acumulação primitiva é o momento necessário para a formação do capital em que os produtores se convertem em proletários e suas condições de trabalho em capital. O capital se define como uma relação social que se estabelece pela intermediação de coisas (mercadorias). Assim se estabelecem as condições da modernização se desenvolvendo uma sociabilidade abstrata baseada no dinheiro (Fredric Jameson denomina cultura do dinheiro). A reprodução no mundo moderno se realiza através de violências sempre repostas que são naturalizadas no contexto social. Novas materialidades (que produzem novas espacialidades) são produzidas por abstrações para reproduzir abstrações. Segundo Alfredo 
(2006), a abstração é o elemento identitário do moderno. No desenvolvimento das forças produtivas, a modernização se apresenta como um movimento abstrato/concreto de reprodução social baseada na acumulação necessariamente expropriatória, produzindo e reproduzindo cisões e separações no âmbito do social. Nesse sentido, para desvendar o mundo moderno é necessário desvendar as mediações abstratas que determinam a realidade. A modernização pode ser pensada como uma acumulação de abstrações, tomando o trabalho abstrato por base. O trabalho abstrato, determinado temporalmente a partir da acumulação primitiva se realiza como efetividade do capital. As acumulações do moderno são acumulações do trabalho na sociabilidade que necessita do trabalho como mais trabalho. Nessa forma, o trabalho só se efetiva, socialmente, através de uma sociabilidade determinada, cuja finalidade é a reprodução do valor, que exige uma simultaneidade dos momentos do capital.

\section{O TRABALHO ABSTRATO}

A história mundial nada mais é que a criação do homem pelo trabalho humano. Através do trabalho o homem humaniza a natureza e se humaniza a si próprio, se apropriando do mundo humano através do refinamento dos sentidos humanos. No reino da propriedade privada capitalista, no entanto, os homens se relacionam através da mediação de coisas. A economia moderna reduz as necessidades humanas à necessidade de dinheiro. Ou seja, as necessidades concretas do homem, produzidas em seu processo de humanização, são reduzidas a uma abstração, empobrecendo as capacidades humanas, simplificando o homem. A indústria "faz do trabalhador um ser destituído de sentidos e de necessidade, da mesma maneira que transforma a sua actividade em simples abstracção de toda a actividade" , e a economia política corrobora com esta condição do trabalhador. A reprodução da vida se reduz à abstração do dinheiro, através do qual pode-se conquistar (ter) "tudo" (usufruir de todas as benesses da sociedade). Ao mesmo tempo impõe-se o fato de que a finalidade do dinheiro é a sua própria reprodução enquanto dinheiro, ou seja, o seu conteúdo é esvaziado de qualquer necessidade concreta do homem. O homem está submetido à abstração dinheiro, na falsa ilusão de que o dinheiro (poupado) lhe satisfará as necessidades. É a reprodução da alienação, pois o dinheiro não é mera mediação, mas é um fim em si mesmo. Assim, estamos diante de uma contradição fundamental e crítica, já que o que humaniza os homens é o fato de ele produzir os seus próprios meios de vida e no capitalismo, a reprodução se dá pela alienação do trabalho pela exploração do trabalho alheio. No caminho do entendimento deste processo, é necessário pensar a propriedade privada através de seu fundamento, o trabalho. A divisão do trabalho, expressão do caráter social do trabalho se transforma em instituição alienada da atividade humana, como real atividade da espécie.

Segundo Giannotti, a obra de Marx pretende ligar o pensamento ao movimento da história, partindo "do inventário daqueles pressupostos que determinam as condições materiais de vida dos indivíduos" 8 . Ou seja, critica uma filosofia "que localiza a verdade no movimento geral do sistema" ${ }^{9}$. Com isso, para Marx, o pressuposto da história da humanidade é a existência material dos indivíduos e a reprodução de seus meios de vida. Como diz Giannotti:

Para que haja uma história da humanidade cabe, em primeiro lugar, pressupor a existência de indivíduos vivos, corporal e socialmente organizados, diferenciando-se dos animais à medida que produzem seus próprios meios de vida. E o modo como produzem tais meios depende do arranjo e da constituição de outros meios preexistentes. Mas somente asseguram sua existência quando conseguem exteriorizar a própria vida: eles vêm a ser segundo a maneira como se externalizam. O aumento da população produz a divisão do trabalho, sendo que diferentes graus do desenvolvimento dessa divisão também determinam a mútua relação dos indivíduos entre si, tendo em vista os materiais, os instrumentos e os produtos mobilizados pela atividade produtiva ${ }^{10}$ 
Esses argumentos corroboram para a afirmação de que o movimento da história se dá no desenvolvimento das forças produtivas, pois

determinados indivíduos se tornam ativamente produtivos segundo formas determinadas, necessitando para isto travar relações sociais e políticas. À observação empírica cabe, então, mostrar como cada superestrutura social e política depende de sua infra-estrutura produtiva. Desse modo, até mesmo a articulação da sociedade e do estado provém do processo de vida dos indivíduos, processo de determinação que atinge a produção de idéias, de representações e da própria consciência ${ }^{11}$.

Caminhando ainda com Giannotti (baseado neste momento do seu estudo nas idéias da Ideologia Alemã), constatamos a essência do homem na atividade. É através da atividade que ele se contrapõe em relação à natureza e produz-se enquanto homem, produzindo os meios de sua reprodução. É também desta relação homem-natureza que nasce a própria sociedade, já que neste percurso cria-se a necessidade de trabalhos alheios, através de uma divisão do trabalho, que é unificada pela necessidade de trocas comerciais. "O fato da história tem como condições de sua existência a finitude dos homens e o enraizamento deles na natureza" ${ }^{12}$. Com isso, ao colocar a essência do homem na atividade, identifica-se o pressuposto central da vida (social) humana, pois "homens precisam viver a fim de "fazer história"" 13 . Assim, são fatos concretos que determinam a história e a cada momento histórico implica numa superação das condições de existência. Ainda para Giannotti:

Esmiucemos as condições de existência desta história. Ela requer: 1) a produção de meios para a satisfação dos
carecimentos humanos; 2) a satisfação dos carecimentos, embora os atos de satisfazer e de empregar instru-
mentos produzam novos carecimentos — note-se que esta é a primeira ação (Tat) propriamente histórica; 3) a
produção de outros homens, por conseguinte, constituição de uma família e início da relação especificamente
social; 4) a produção pelo trabalho e a geração pelo sexo, que se dão simultaneamente, quer como relações
naturais, quer como relações sociais, no sentido de ações conjugadas de vários indivíduos convergindo para
certos fins. Esses são momentos, aspectos relevantes de um processo, que somente a imaginação pode sepa-
rar. Mas importa aos autores, nessa época, ressaltar que os homens, devendo produzir suas vidas de forma
determinada, o fazem associando organização física e consciência. Em suma, interessa-lhes a determinação
social e epocal das formas de consciência, vale dizer, das ideologias ${ }^{14}$.

A história humana se realiza na reprodução de suas próprias condições de existência, na necessidade humana de transformar os elementos da natureza para o seu usufruto, assim como com a necessidade de trocas entre os próprios homens, através da divisão do trabalho. Porém, no percurso do desenvolvimento das forças produtivas, se separam o trabalho e o usufruto e nesse movimento criam-se as condições da separação entre o pensamento e a prática mais imediata. Com esse encaminhamento, constitui-se um pensamento dominante que insere os momentos da história na reprodução das condições de dominação.

Os pensadores dessa classe podem assim nutrir a ilusão de que tais interesses particulares constituem os interesses da sociedade como um todo, deslocando pois o particular para que se transforme em universal. Cada nova classe dominante amplia desse modo suas bases de dominação, operando uma "negação radical das condições sociais" (Gesellschaftszustände) válidas até então (DI, 3, 48). Da mesma maneira que a história mundial vai se configurando graças à ampliação do processo de dominação, igualmente se ampliam as formas de consciência, até que a radicalização final do processo histórico termina por conformar a ilusão de que a consciência de si tem a capacidade mística de se determinar a si mesma (DI, 3, 48-9) ${ }^{15}$.

No capitalismo se exacerbam as forças opostas se constituindo em contradições. A superação das contradições seria realizada através de um processo que se efetivaria no interior das relações de produção. 
Assim, o processo histórico de apropriação da natureza pelo homem é ao mesmo tempo um processo concreto (produção das condições materiais de existência) e abstrato, pois o homem se distingue e se confronta com a natureza (sem deixar de fazer parte dela). Ou seja, é um processo de abstração que, no desenvolvimento das forças produtivas distingue também os homens entre si, através das diferentes (e contraditórias) formas sociais de apropriação da riqueza social produzida.

No processo de separação do pensamento da prática se dá a alienação do trabalho no capitalismo. A atividade, essência do homem social, (da humanização do homem) é transformada em potência estranha ao homem. A própria cidade enquanto local da vida (reprodução dos meios de vida) se torna exterioridade para os habitantes.

Segundo Kurz, o trabalho não é supra-histórico, como é difundido, mas foi instituído pela ética do trabalho no contexto religioso-ideológico do protestantismo e depois foi reproduzido inclusive pelo movimento operário. "O socialismo do movimento operário nunca esteve distante dessa criação fetichista da motivação do antigo protestantismo" ${ }^{16}$, e "transformou o trabalho numa religião secularizada" ${ }^{17}$ (p.19). Desenvolvendo os argumentos para mostrar a não "naturalidade" do trabalho, afirma ele que "Em sua forma especificamente histórica, o trabalho nada mais é do que a exploração econômica abstrata, em empresas, da força de trabalho humana e das matérias-primas". E acrescenta: "Mas o trabalho, nessa curiosa forma abstrata, pode ser definido também como atividade que, de maneira igualmente curiosa, traz sua finalidade em si mesma" (p.18). Assim, no capitalismo, o trabalho toma uma forma histórica que não tinha antes. Antes, por causa do grau relativamente baixo do desenvolvimento das forças produtivas, "o trabalho era, portanto, uma necessidade imposta pela natureza, porém precisamente por isso nenhum dispêndio abstrato de força de trabalho e nenhuma atividade social que traz em si sua própria finalidade" ${ }^{18}$. Ou seja, o trabalho torna-se uma tautologia, o homem trabalha porque tem que trabalhar, o trabalho se revelando assim como uma coação social. "A forma de reprodução social da mercadoria torna-se uma "segunda natureza", cuja necessidade apresenta-se aos indivíduos igualmente insensível e exigente como a da "primeira natureza", apesar de sua origem puramente social" 19. "A sociedade de trabalho como conceito ontológico seria uma tautologia" ${ }^{20}$. Com isso, podemos delinear um certo percurso de abstração do trabalho que vai do trabalho produtor de valor de uso, ao trabalho produtor de mercadoria (trabalho produtor de mais valia), e com a abstração do dinheiro em capital, cria-se a necessidade de sempre produzir mais dinheiro. Ou seja, cria-se aí uma finalidade tautológica, pois a finalidade do dinheiro é produzir mais dinheiro. Diz Kurz que "O trabalho vivo aparece apenas como expressão do trabalho morto que se tornou independente, e o produto concreto, sensível, como expressão da abstração inerente ao dinheiro" ${ }^{21}$.

Os recursos humanos e materiais (força de trabalho, instrumentos, máquinas, matérias-primas e materiais) não podem mais ser entendidos apenas como uma parte do metabolismo entre os homens e a natureza a serviço das satisfações materiais. Passaram a servir apenas para a auto-reflexão tautológica do dinheiro como "mais dinheiro" 22 .

Ainda diz ele:

Necessidades sensíveis somente podem ser satisfeitas, portanto, pela produção não sensível de mais valia, que se impõe cegamente como produção abstrata, em empreendimentos industriais, de lucro. A troca no mercado deixa de servir para a mediação social de bens de uso, servindo, ao contrário, para a realização de lucro, isto é, para a transformação de trabalho morto em dinheiro, e a mediação dos bens de uso passou a constituir somente um fenômeno secundário desse processo essencial que se realiza na esfera monetária ${ }^{23}$. 
Kurz faz uma crítica à ontologia do trabalho e à identidade da classe trabalhadora proveniente dessa ontologia. Seria uma mistificação dessa classe trabalhadora, que não fez a crítica radical do sistema produtor de mercadorias. Se no capitalismo não há sujeito, aceitando o argumento de Kurz, nessa sociabilidade constituída no socialismo real o sujeito também era totalmente sujeitado pelo Estado, o que representa por outras vias que não a do mercado diretamente, estar sujeitado ao capital.

Para Kurz, no socialismo real o Estado era o elemento de desenvolvimento do capital ("do qual o Estado é apenas um elemento, e isso já no início da modernidade, no processo de constituição dessa formação social" ${ }^{24}$ ). "Com isso, o comunismo transformou-se numa ideologia legitimadora "proletária" da modernização coativa burguesa recuperadora" 25 . Assim, no socialismo continuaria o processo de modernização:

\begin{abstract}
Essa continuidade se estende desde o absolutismo esclarecido o Ocidente até o atual Estado de crescimento, e inclui ainda o socialismo real baseado na economia de guerra; o fim comum a ambos consiste em impor a subordinação das necessidades, finalidades e intenções humanas à riqueza nacional abstrata de um sistema produtor de mercadorias e ao seu crescimento e também ao direcionamento sistemático dos homens a esta finalidade "sem sentido" 26 .
\end{abstract}

O mundo moderno se revela como um conjunto de sub-sistemas que (ideologicamente) se auto-explicam tautologicamente. A modernização como produção de uma sociabilidade é reproduzida por uma prática espacial, num espaço específico que é produzido e reproduzido no contexto da reprodução social, como exigência da simultaneidade posta pelo processo do capital. A exigência de simultaneidade faz com que haja uma abstração do tempo através do espaço. Nesse sentido, o espaço é produzido como infraestrutura para a melhor circulação do capital e como produção de mais valor ele mesmo. Muitos autores salientam a importância que o espaço passa a ter na resolução de crises de acumulação. Para Lefebvre, a produção do espaço exerce um papel fundamental nesse sentido; Harvey fala em necessários rearranjos espaciais, onde a destruição de ativos passa a ser um momento necessário para novas valorizações; Neil Smith fala sobre a recriação contínua de novas fronteiras econômicas no espaço urbano; César dos Santos mostra como a reprodução ampliada do capital exige transformações profundas no espaço urbano, em conseqüência de uma necessária reposição contínua da acumulação primitiva (do espaço), tendo em vista o caráter crítico do capital. Diz que "A ligação entre as crises e a produção de uma nova realidade espaço-temporal do capitalismo nas metrópoles modernas é o eixo de transformação do espaço urbano predominante durante quase todo o século $\mathrm{XX}$ "27, e ainda "A sobreacumulação de capitais tem sido o calcanhar de Aquiles para os inversionistas que devem realizar sucessivamente novos investimentos lucrativos. Associadas à sobreacumulação, as baixas taxas de lucro têm estimulado recorrentes processos migratórios intersetoriais e espaciais de capitais" ${ }^{28}$.

Olgária Matos demonstra como no processo de modernização há a passagem de uma razão autônoma para uma

razão instrumental, que busca tão somente a eficiência e a produtividade e transforma o indivíduo em instrumento de si próprio. Tal é a razão que comanda a passagem do espaço qualitativo da cidade - no qual o homem pode se reconhecer - ao espaço quantitativo e abstrato, preparando a transmutação da cidade como valor-de-uso, em metrópole, isto é, valor de troca, segundo os mesmos mecanismos que atuam no processo de trabalho e que determinam a onipresença do trabalho abstrato na sociedade. É esta a temporalidade presente nas sociedades produtivistas, nas quais o trabalho do indivíduo - qualitativo, heterogêneo - é governado pelo trabalho quantitativo, do qual somente subsiste uma qualidade, comum a todas as formas de trabalho e que as torna comensuráveis: "Todo ato de produção reclama um certo tempo". Quer dizer, o homem se torna escravo 
de seu tempo: "O tempo é tudo, o homem não é mais nada, nada mais que a materialização do tempo" (Marx, Miséria da Filosofia). Para este tempo o pêndulo é a medida exata da atividade de dois operários, como o é da velocidade de duas locomotivas; a quantidade decide tudo, hora por hora, dia por dia, "o homem é só a carcaça do tempo. Não é uma hora de homem que vale a hora de outro homem, mas o homem de uma hora vale um outro homem de uma hora" (idem). Trata-se de uma relação de igualdade abstrata entre indivíduos concretamente desiguais, isto é, incomparáveis. Para a sociedade o indivíduo só conta enquanto engrenagem destinada a realizar um gesto particular. É o presente produtivista da economia de mercado que domina a Metrópole. Esta desaloja as últimas sobrevivências da produção doméstica e a troca direta de mercadorias: "A exatidão calculista da vida prática", diz Simmel, "que a economia do dinheiro criou corresponde ao ideal de Ciência Natural: transformar o mundo em problema aritmético, dispor todas as partes do mundo por meio de fórmulas matemáticas (...). Através da natureza calculativa do dinheiro, uma nova precisão (...), uma ausência de ambigüidade nos acordos e combinações surgiram nas relações de elementos vitais como externamente esta precisão foi efetuada pela difusão universal dos relógios de bolso" (Simmel, A Metrópole e a vida mental) 29.

No processo de produção do próprio homem contraditoriamente o homem se esvazia enquanto ser de atividade criativa, esvaziando o conteúdo concreto do tempo e consequentemente esvaziando a apropriação concreta do espaço. A transformação da atividade criativa em trabalho que produz valor de troca se revela um processo violento, onde trabalhos qualitativamente diferentes e valores de uso diferentes são tornados equivalentes, reduzidos à quantidade de trabalho abstrato geral.

\section{A URBANIZAÇÃO DA METRÓPOLE COMO REPRODUÇÃO DA ABSTRAÇÃO}

Os processos que hoje se realizam na metrópole de São Paulo, produzindo e reproduzindo a sua urbanização nos colocam diante da necessidade de, partindo do que aparece como concreto, construir as abstrações (mediações) necessárias para o seu entendimento. Inserida no movimento geral da economia, a metrópole vive a passagem da hegemonia do capital industrial para a hegemonia do capital financeiro nas diretrizes de sua produção. Isso apontaria para o fato de que a urbanização da metrópole, mais do que nunca, entraria no jogo da valorização de capitais da esfera financeira. Diante deste contexto, em nossas pesquisas analisamos espaços de desindustrialização que, com a saída de indústrias e a desagregação como espaços industriais, disponibilizam grandes terrenos para as estratégias dos agentes hegemônicos da produção do espaço. Os espaços que agora se desindustrializam são tomados como vazios a serem preenchidos pelas estratégias do setor imobiliário articulado aos setores da construção civil e ao financeiro. Assim, espaços caracteristicamente industriais, com uma sociabilidade possível construída no processo de industrialização, são perpassados pelas estratégias da valorização, que ao mesmo tempo em que se aproveitam da degradação ocasionada pelo recuo industrial, passam a constituir uma outra sociabilidade (outras espacialidades) que ampliam o caráter da metrópole como exterioridade, sobretudo para os moradores destes lugares, que vivem negativamente o processo, pois se aprofundam os mecanismos de segregação no urbano. A tendência que o processo aponta é a da valorização, que se realiza com a produção (nestas áreas) de uma outra espacialidade ligada ao consumo e à residência de uma classe médiaalta e alta. Grandes condomínios residenciais totalmente fechados ao entorno, casas de shows e eventos que levam um outro movimento às ruas, o que corrobora para uma mudança radical nos usos do espaço. Estamos diante portanto de uma transformação radical do lugar. Se antes a sociabilidade produzida pela indústria já propunha uma vida cotidiana fragmentada, agora com o avanço da valorização os laços da sociabilidade anterior são quebrados avassaladoramente. O espaço concreto da vida se reduz ainda mais diante do "inexorável” desenvolvimento da metrópole. A inserção destes espaços nos circuitos dinâmicos da economia os realiza enquanto espaços onde as lógicas abstratas do processo do capital atuam

Revista da ANPEGE. v. 5, 2009 
concretamente, desmantelando possíveis apropriações construídas ao longo do processo histórico. $\mathrm{O}$ espaço produzido pelos agentes hegemônicos não só constituem grandes equipamentos urbanos visíveis na paisagem, mas também se realiza através de uma construção discursiva difundida na sociedade. Os conflitos e contradições se esfarelam diante do discurso do desenvolvimento. Um discurso empresarial se institui como verdade inquestionável, tomando a cidade (e a sociedade) como força produtiva para o capital. No contexto do cotidiano instaurado, a vida em todos os níveis é programada, regulada por necessidades exteriores e conflituosas com a própria reprodução da vida, tornando todos os momentos da vida produtivos para o capital.

\section{REFERÊNCIAS BIBLIOGRÁFICAS}

ALFREDO, Anselmo. O mundo moderno e o espaço: apreciações sobre a contribuição de Henri Lefebvre. Geousp. Espaço e Tempo. |São Paulo, n. 19, 2006.

CARLOS, Ana Fani Alessandri. São Paulo: do capital industrial ao capital financeiro. In: Ana Fani Alessandri Carlos e Ariovaldo Umbelino de Oliveira (orgs.). Geografias de São Paulo - A metrópole do século XXI. São Paulo: Editora Contexto, 2004.

CORRÊA, Roberto Lobato. Espaço, um conceito chave da Geografia. In: CASTRO, I. E.; CORRÊA, R. L.; GOMES, P. C. C. (Orgs.). Geografia: Conceitos e Temas. Rio de Janeiro, 2007, $10^{\mathrm{a}}$ ed..

GIANNOTTI, José Arthur. Certa herança marxista. São Paulo: Companhia das Letras, 2000.

KURZ, Robert. O Colapso da Modernização. Da derrocada do socialismo de caserna à crise da economia mundial. São Paulo: Paz e Terra, 1999, 5 a edição.

MATOS, Olgária. A Cidade e o Tempo: algumas reflexões sobre a função social das lembranças. In: História Viajante: Notações Filosóficas de Olgária Matos. São Paulo: Studio Nobel, 1997.

MARX, Karl. Para a Crítica da Economia Política. In: Os Economistas, São Paulo: Abril Cultural, 1982. . Terceiro Manuscrito. In: MARX, Karl. Manuscritos Econômico-Filosóficos. Lisboa: Edições 70, 1993.

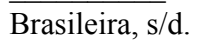

A Chamada Acumulação Primitiva. In: O Capital, livro I, volume II. Rio de Janeiro: Civilização

SANTOS, César Ricardo Simoni dos. Dos negócios na cidade à cidade como negócio: uma nova sorte de acumulação primitiva do espaço. Cidades, v. 3, n5, 2006, p. 101-122.

Recebido em abril de 2009

Aceito em agosto de 2009 